\title{
EL INTERÉS MORATORIO EN EL DERECHO DEL TRABAJO
}

\section{Consuelo Ferreyra y Leonardo Oscar L'argentiere ${ }^{1}$}

Sumario: I. Introducción II. Justificación del instituto A. Objetivo directo B. Objetivo indirecto III. La potestad judicial A. La tasa de interés 1. La regla. 2. Supuestos especiales en Riesgos de Trabajo. a) El decreto 1694. b) Ley 26.773. c) Ley 27.348. d) Intereses al fondo. B. El curso de los intereses, dies a quo y dies ad quem en la Ley de Riesgos de Trabajo (Ley 24.557). IV. El anatocismo. V. Conclusiones finales.

Resumen: Si bien el debate acerca de la actualización monetaria mediante la aplicación de intereses no es nuevo, si no por el contrario ha sido objeto de innumerables discusiones doctrinarias y jurisprudenciales, lo que se pretende es hacer un repaso sobre la naturaleza jurídica de los mismos y analizar la regulación normativa en materia de Ley de Riesgos de Trabajo especialmente en lo referido a la potestad judicial, la tasa de interés aplicable y los periodos a considerar. Finalmente se analizará el instituto del anatocismo y su regulación en la materia objeto de estudio.

Palabras clave: Intereses. Moratorias. Riesgos. Tasa de interés. Anatocismo

\section{I.- Introducción}

La doctrina y la jurisprudencia no han estado contestes en oportunidad de fijar intereses aplicables al capital de la condena.

Tanto la tasa de interés como los periodos a considerar y aun su naturaleza jurídica (resarcitorios, moratorios, compensatorios, punitorios) han sido motivo de debate y diferencias que sirvieron de argumento a recursos ordinarios y extraordinarios. Ocurre que los intereses constituyen materia íntimamente ligada a la oportunidad histórica de la condena, a la situación socio-económica y la orientación política considerada como el conjunto de valores privilegiados.

La sanción del Código Civil y Comercial, de aplicación impostergable en cuanto marco de derecho común, ha dedicado nuevos capítulos al tema en debate y multiplicado los cuestionamientos.

Asoman múltiples interrogantes: ¿Cuál es la interpretación justa? ¿Cuál la facultad del

1 Master en Derecho Empresario en la Universidad Austral, docente de grado y posgrado y Especialista en Derecho Laboral (UNC-UNL-UCC), respectivamente. E-Mail de contacto:consueloferreyra@gmail.com. 
magistrado? ¿Cuál es el "dies a quo”? ¿Qué periodos están sujetos a interés? ¿Qué interés corresponden a cada periodo? ¿Cómo juega la figura del anatocismo?

Abordaremos estas cuestiones teniendo especialmente en cuenta la regulación en materia de Ley de Riesgos de Trabajo.

\section{Justificación del instituto}

Para que la obligación ya traducida a dinero tenga efecto cancelatorio razonablemente justo es necesario que el importe del pago satisfaga la obligación originaria con más un plus que indemnice al acreedor el daño adicional provocado por la demora, o mínimamente respete (actualice) el valor real del crédito.

Eventualmente podríamos considerar un tercer aspecto que es el castigo o punición al deudor moroso. Así podríamos decir que la fijación de intereses persigue fines directamente relacionados con el caso concreto y otro que es genérico o común a todas las situaciones.

A. Objetivo directo: El interés moratorio es una herramienta necesaria para reparar el daño adicional que sufre el acreedor ante la falta de pago oportuno. Es utilizado para garantizar una indemnización integral ${ }^{2}$ o un legítimo resarcimiento ${ }^{3}$, mediante la implementación de una tasa que refleje la realidad económica imperante en un determinado periodo de tiempo. Se incremente en periodos de depreciación monetaria, elevada inflación o en respuesta a la actitud asumida por la parte, mientras que puede ser disminuida en periodos de estabilidad ${ }^{4}$, frente a resultados excesivos, irracionales 0 desproporcionados 5 .

B. Objetivo indirecto: Apunta a la satisfacción de un objetivo más general que consiste en desalentar la morosidad, la litigiosidad y la especulación, además de garantizar el cobro al mayor número posibles de acreedores.

Para ello se debe escoger, con rigor, una tasa equilibrada que se ajuste a la ponderación de los parámetros económicos objetivos. No debe ser irrisoria porque alentaría incumplimientos, favorecería el enriquecimiento indebido del deudor moroso y promovería renuncias ilegitimas (art.12, LCT), forzando a los actores a negociar su crédito en menos y apresuradamente. Tampoco elevada, ya que propendería a fomentar la inflación y el surgimiento de situaciones jurídicas injustas, desproporcionadas, irracionales o abusivas (art. 10 CCCN).

Resumiendo, la tasa de interés que se fije debe: 1) garantizar un resarcimiento íntegro; 2) procurar evitar la aplicación mecánica de fórmulas arbitrarias; 3) resguardar las garantías constitucionales como el derecho a la integridad del patrimonio ya una decisión justa y fundada. Esto es con identificación de pautas objetivas que reflejen la realidad económica del periodo a considerar y el control de justicia; 4) se tendrá presente durante el

\footnotetext{
2 TSJ, sentencia n 34, 29/04/2015, autos: "Higa Ricardo Alberto C/ HOSPITAL ITALIANO".

3 “...la utilización de intereses constituye solo un arbitrio tendiente a obtener una ponderación objetiva de la realidad económica a partir de pautas de legítimo resarcimiento",CSIN, (26/02/2019); recurso directo en autos "Bonet, Patricia Gabriela por sí y en rep. hijos menores c/ Experta Aseguradora de Riesgos del Trabajo Sociedad Anónima y otros".

4 "...se redujo dicha tasa, en virtud de haberse tornado excesiva frente a la estabilidad del mercado financiero y la consiguiente baja de interés" TSJ, sent. 83/05 "César, Carlos Alberto c/Municipalidad de Rio Ceballos - inc."

5 "Que tal situación se verifica en el caso toda vez que el a quo, sin proporcionar ningún -tipo de fundamentación seria que justifique su decisión, fijó dogmáticamente una suma resarcitoria que resultó ser veinticuatro veces superior a la pretendida", CSJN, 8/10/2019, "Recurso directo en autos: "Ripp, Juan Ignacio c/ Personal Collect S.A. s/ despido".
} 
silogismo que el magistrado puede morigerar ${ }^{6}$ la tasa (art. 771, CCCN) o incluso recurrir a la doctrina del "esfuerzo compartido", cuando las circunstancias lo aconsejen.

\section{La potestad judicial}

Durante la vigencia del Código de Vélez la selección de la tasa aplicable estuvo reservada a la potestad del magistrado.

A partir de la vigencia del CCCN (1/8/2015), la redacción del art. 768 del CCCN parece despojar al juzgador de la facultad para determinar la tasa de interés moratorio ${ }^{7}$ y depositarla en cabeza del BCRA.

Pero éste no ha sido el criterio adoptado por el TSJ ${ }^{8}$. El tribunal cimero, sin desmerecer la facultad del $\mathrm{BCRA}^{9}$, considera conveniente que sea el juzgador quien escoja la tasa aplicable al caso, aunque ahora asistido de una "canasta de tasas"10

En la jurisprudencia de la Cámara Única del Trabajo de Córdoba se ha mantenido esta línea, salvo contadas excepciones, y se sigue aplicando el precedente "Hernández"11.

Esto tiene por ventaja la previsibilidad, la seguridad jurídica ${ }^{12}$ la igualdad ante la ley ${ }^{13}$ y el respeto al valor del precedente (función nomofiláctica ${ }^{14}$ ).

Pero también se utiliza para justificar su aplicación mecánica y descontextualizada cuando las circunstancias del caso demandan una tasa diferente, ello atenta contra la indemnidad del crédito, el progreso en el reconocimiento de derechos, la justicia social ${ }^{15}$, la equidad, la buena $\mathrm{fe}^{16} \mathrm{y}$ el rol judicial activo esperado en el marco del CCCN. ${ }^{17}$

6 CSJN, "Bonet"; ob. cit.

7 Facultad que a texto expreso conserva en los intereses compensatorios (art. 767,CCyCom.).

8 "La previsión del artículo 768 inciso c) no implica la delegación al Banco Central de la fijación de la tasa, sino que siempre será el juez el que la determinará. Las tasas fijadas por las reglamentaciones del Banco Central servirán como pauta que podrá ser utilizada por el juez en esta tarea (Urruti, Bonino, Gonzalez Zavala, Churruarin, Moia, Scotto Lavina, Rey, Márquez, Borda, Compiani, Azar, Bliss, Viale)". TSJ, sentencia 112 (1/11/2016), autos: "Nasi, Alberto Hugo Saúl C/ Rosli, Never Alberto y otros". Con cita a la conclusión 20.1 de las XXV Jornadas Nacionales de Derecho Civil, publicada en https://es.slideshare.net/ ninanor2003/conclusiones-xxv-jornadas-nacionales-de-derecho-civiloctubre-2015-baha-blanca, según consulta realizada con fecha 20/3/2020.

9 "El banco tiene por finalidad promover, en la medida de sus facultades y en el marco de las políticas establecidas por el gobierno nacional, la estabilidad monetaria, la estabilidad financiera, el empleo y el desarrollo económico con equidad social” (Art. 3, Carta Orgánica del Banco Central de la República Argentina). "Históricamente las tasas han estado vinculadas a planes de gobierno y exceden ampliamente la realidad judicial en general y la de cada caso en particular. Las tasas se entrelazan con el tipo de cambio, la inflación, el ingreso de divisas, capitales golondrinas, exportación de materias primas y su valor internacional, importación, promoción de la industria local, el crédito, etc. ...es tarea de los jueces la determinación de la tasa de interés, y la derivación que el inc. c) del art. 768 CCCN formula a las tasas del Banco Central es sólo a los fines de que los magistrados en ejercicio de tal facultad, seleccionen la tasa entre cualquiera de las fijadas por las reglamentaciones de la autoridad monetaria, teniendo en cuenta las particularidades de la causa, fundando la decisión adoptada con una motivación razonable (art. 3, CCCN)",autos "Nasi" citados.

10 IBÁÑEZ (h), Carlos Miguel en http://jornadasderechocivil.jursoc.unlp.edu.ar/wp-content/uploads/sites/10/2017/08/Ib\%C3\%A1\%C3\%B1ez-CarlosMiguel-h-INTERESES-JUDICIALES.Comisi\%C3\%B3n-3.pdf., consultada el 15/1/2020.

11 TSJ, “Hernández Juan Carlos c/Matricería Austral S.A.-demanda- Rec. de casación”, (sentencia Nº 39 del TSJ, 25/6/2002). Ratificado por el TSJ en forma sostenida y reiteradamente,vgr. “Pérez Oscar Darío C/ Carra Martín, y otro- Exp. 329992”, sentencia N¹29,7/9/2017.

12 La palabra seguridad proviene de la palabra latina, la cual deriva del adjetivo (de secura) que significa estar seguros de algo y libres de cuidados.

13 “...todos los habitantes son iguales ante la ley..." (art. 16 Constitución Nacional). "Todas las personas son iguales ante la ley" (art.2 Declaración Americana de Derechos y Deberes), "todos son iguales ante la ley" (art. $7^{\circ}$, Declaración Universal de Derechos Humanos); "todas las personas son iguales ante la ley..." (art. 24 Convención Americana sobre Derechos Humanos - Pacto de San José de Costa Rica), etc.

14 "Esta Sala no puede desentenderse de la función unificadora a su cargo, debiendo primar el principio de igualdad de los ciudadanos ante la ley. Estas razones explican que se modifique el interés dispuesto y se emplace la tasa pasiva promedio nominal mensual del BCRA con más el dos por ciento mensual, conforme la causa "Hernández Juan Carlos c/ Matricería Austral S.A., Sent. N. ${ }^{\circ} 39 / 02$. En igual sentido de esta Sala, Sents. Nros. 129/17 y 181/18” TSJ Sala Laboral Cba., Sent. N. ${ }^{\circ}$ 1, 4/2/2020, “Quinteros María del Carmen c/ Consolidar A.R.T. S.A. - Ordinario - Incapacidad” Recurso de casación”, Trib. de origen: Cámara del Trabajo, Villa María.

15 "Proveer lo conducente al desarrollo humano, al progreso económico con justicia social..." (art. 75, inc. 19 CN).

16 “...se decidirá conforme a los principios de la justicia social, a los generales del derecho del trabajo, la equidad y la buena fe" (art. 11 LCT).

17 “...otorgarles mayores potestades a los jueces (con el objeto de resolver el caso con el mayor acercamiento a la realidad de los hechos y las particulares 
Por ello la solución que se adopte debe estar debidamente fundada ${ }^{18}$ a fin de evitar soluciones arbitrarias o la mecánica aplicación de fórmulas matemáticas abstractas. Si bien la determinación de las pautas en la aplicación de intereses (tasa y curso) es materia reservada al tribunal de la causa, remiten al examen de cuestiones de hecho y de derecho común, ajenas a la instancia extraordinaria, excepto la tacha de arbitrariedad por vicio en la fundamentación. ${ }^{19}$

Tampoco integrará la cosa juzgada en sentido material y admite su modificación para períodos posteriores. La tasa fijada se aplica durante el cómputo de intereses previsto en la sentencia (desde el dies a quo hasta el dies ad quem), pero nada obsta a que pueda variar para el futuro si se modifican las condiciones socio-económicas antes del pago. ${ }^{20}$

\section{La tasa de interés \\ La regla (tasa compuesta)}

Como dijimos anteriormente la elección de la tasa queda dentro de las facultades reservadas al tribunal de la causa, pero su decisión debe estar debidamente fundada.

Dicha tasa se compone de dos elementos: a) la Tasa Promedio Pasiva (TPP) que publica el BCRA y b) un porcentaje adicional que refleja el componente retributivo para el periodo a considerar. Entonces a la tasa de referencia (TPP BCRA) se le adiciona un porcentaje retributivo que podríamos llamar de ajuste ${ }^{21}$ que se obtiene a través de datos objetivos que reflejan el índice inflacionario ${ }^{22}$, la pérdida del valor adquisitivo de la moneda y las circunstancias concomitantes que rodean el caso concreto.

De la combinación de ambos elementos se extrae una fórmula que procura garantizan un importe que cubra el daño adicional provocado por el atraso en el pago.

A continuación, y a modo ilustrativo vamos a formular un cuadro comparativo entre el interés judicial de uso mayoritario y el índice inflacionario de los últimos años. Los resultados obtenidos surgen de la "planilla de cálculos judiciales" (página del poder judicial: TPP + $2 \%$ ) y del índice de inflación anual suministrado por el Instituto Nacional de Estadísticas y Censos (INDEC).

\footnotetext{
circunstancias de las partes) de ningún modo vulnera el proceso diseñado en la Constitución Nacional. Por el contrario, resulta indispensable para lograr la composición "real" del conflicto. Únicamente bajo dichas premisas nos acercaremos a los fines mismos de la jurisdicción: reestablecer la paz social quebrantada o a punto de serlo. Ello no es posible cuando lo decidido es sólo una "ficción de justicia". KERN, Luciano Minetti "El perfil del Juez a partir de la entrada en vigencia del Código Civil y Comercial. Nuevos desafíos y razones para dejar atrás prácticas disvaliosas. Hacia un Juez Constitucional", en . http://servicios.jusrionegro.gov.ar/inicio/comunicacionjudicial/index.php/especiales/item/527-perfil, consultado el 23/3/2020.

18 Art. $63 \mathrm{LPT}$, art. $3^{\circ} \mathrm{CCCN}$, art. 155 Constitución Provincial, correlativos y concordantes.

19 ROSATTI, Horacio “... a partir de la sentencia de Fallos: 317:507 (Banco Sudameris) esta Corte ha adoptado el criterio según el cual la tasa de interés a aplicar como consecuencia del régimen establecido por la ley 23.928 queda ubicada en el espacio de razonable discreción de los jueces de la causa y es ajena a la vía del art. 14 de la ley 48", CSJN, "Bonet"; cit (voto en disidencia).

20 “...La alteración de la tasa fijada en la sentencia respecto de un período posterior a la misma, en función de la variación de la coyuntura existente al momento de determinarla, lejos de comprometer la autoridad de la cosa juzgada, tiende a tutelarla al preservar el valor del crédito reconocido. Sólo así se logra "mantener la estricta igualdad de la prestación debida conforme las circunstancias del caso" (C.S.J.N., "Vieytes de Fernández Suc.- v. Provincia de Bs. As.", Fallos 295:973)”, TSJ, Sent. 19, (4/4/2006) “Cossar Marcelo A. c/ R.P.M. S.R.L y Otros. Indem. Ley 24013, etc. Rec. de casación”; ídem TSJ, sent. 166/13, "Olive, José E. c/Entertainment Depot S. A."

$21 \mathrm{El}$ "componente retributivo que habitualmente utiliza esta Sala para ajustar el capital adeudado frente a las diversas fluctuaciones económicas" (sic, el destacado es de mi autoría). TSJ, sent. 3 (20-02-2014) autos: "Martín Pablo Darío C/ MAPFRE ART SA. - Ordinario - Accidente (ley de riesgos) - Recurso de casación e inconstitucionalidad".

22 Se ha expuesto que “...dicho propósito no se satisface con una tasa de interés inferior a la inflación subyacente durante el mismo lapso temporal... El interés moratorio judicial debe integrarse con la tasa pasiva promedio que publica el Banco Central de la República Argentina, más un plus. Mediante la tasa pasiva se reconoce al acreedor el costo de oportunidad en una operación bancaria segura, líquida, y disponible, de donde el promedio publicado por el Banco Central es una alternativa idónea como variable de ajuste", TSJ, sentencia n 34 "Higa c/Hospital Italiano", cit.
} 
En la primera columna vemos la tasa anual que surge de aplicar la formula "Hernández" (desde el 01 de enero al 31 de diciembre de cada año), mientras que en la segunda columna vemos el índice de inflación anual publicado por el INDEC.

$\begin{array}{ccc}\text { AÑO } & \text { HERNÁNDEZ (\%) } & \text { INDEC (\%) } \\ 2016 & 43,82 & 40,9 \\ 2017 & 38,26 & 24,8 \\ 2018 & 50,37 & 47,6 \\ 2019 & 67,05 & 53,8\end{array}$

\section{Supuestos especiales:}

En ocasiones los tribunales han dispuesto reducir el componente retributivo de la formula y ajustarlo al caso concreto. Veremos algunos ejemplos:

\section{El decreto 1694/09:}

Para la CSJN es inaplicable a contingencias anteriores ${ }^{23}$, pero el TSJ lo aplicó de forma inmediata ${ }^{24}$ con la salvedad de que, al establecer pisos mínimos que elevan el importe de la formula redunda en una mejora, en términos monetarios, sobre el capital histórico. En ese contexto el TSJ consideró prudente disminuir el componente retributivo de la tasa de interés y aplicar el 0,50 \% mensual, en remplazo del $2 \%$ que habitualmente se aplica. ${ }^{25}$

Ley 26.773. (B.O.26/9/2012).

EI TSJ adoptó, a diferencia de lo ocurrido con el decreto 1694/09, el criterio de la CSJN ${ }^{26}$ que considera inaplicable la ley 26.773 a supuestos anteriores a su entrada en vigencia ${ }^{27}$ y, por ende, mantuvo la tasa del precedente "Hernández".

La ley 27.348. (B.O. 5/3/2017).

Al igual que lo ocurrido con la ley 26.773, el art. 11 de la ley 27.348 (que modifica el art. 12 de la LRT) en principio se aplican a contingencias posteriores a su vigencia (art. 20, ley 27.348).

En el marco legislativo anterior la indemnización se calcula bajo parámetros históricos sin mecanismo de ajuste (viejo art. 12 de la ley 24.557), lo que produce un daño adicional provocado por la depreciación automática del crédito ${ }^{28}$.

23 CSJN,7/6/2016, "Espósito, Dardo Luis c/Provincia ART".

24 "El planteo encuentra solución en la doctrina de esta Sala, expresada en las causas "Butassi..., Agudo ..., etc." En ellas se ratificó el criterio interpretativo antes adoptado en orden a la vigencia de la ley en el tiempo cuando no se trata de una típica modificación legislativa sino de un intento por vía reglamentaria de superar las deficiencias del sistema resarcitorio anterior" TSJ sentencia 2/2014 "Aldorino Héctor Daniel c/ MAPFRE ART S.A. - Ordinario - Enfermedad accidente (Ley de Riesgos - Recursos de casación e inconstitucionalidad".

25 "Los intereses, desde la fecha del siniestro (14/12/01) hasta la sanción del decreto № 1694/09 (B.O. 06/11/09), se establecen según la tasa pasiva nominal mensual que publica el Banco Central de la República Argentina, destinada a proteger el capital por no haberse abonado en tiempo oportuno, con más un adicional del 0,5\% mensual ("Zapata Angelita E. c/ Ros, Alex y otra" de fecha 27/10/94). Para este lapso, se justifica la determinación de una tasa despojada parcialmente del componente retributivo que habitualmente utiliza esta Sala para ajustar el capital adeudado frente a las diversas fluctuaciones económicas...Ahora bien, a partir del 6/11/09 y hasta su efectivo pago, se considerará la emplazada en la causa "Hernández c/ Matricería Austral" (tasa pasiva B.C.R.A., más el $2 \%$ mensual), a fin de mantener incólume el contenido del crédito", TSJ - sent. n 176 autos: "Latzke Vda. De, Nelly Mara Giovo y Otros c/ Boston Compañía Argentina de Seguros - Ley 24.557 -expedientes remitidos por la justicia federal - Recurso directo". En idéntico sentido TSJ, sentencia 3, 20/2/2014) autos:"Martín Pablo Darío c/ MAPFRE ART SA."

26 CSJN,7/6/2017, "Espósito", citada.

$27 \mathrm{Al}$ alto cuerpo decidió “... desestimar la aplicación de la Ley No 26.773. Lo decidido conduce a modificar los intereses.......conforme doctrina de esta Sala in re: "Hernández...” (Sent. № 39/02) y "Martín” (sent. № 3/14)", TSJ, sentencia 145 (11-08-2015), autos "Fabbio, Fernando D. c/ CNA ART S. A. - Ordinario - Accidente (ley de riesgos)-Recurso de casación".

28 La doctrina expresa: "cuando la ley tarifa o cuantifica una deuda que en esencia es de valor, como es la que responde al resarcimiento de la integridad psicofísica, jamás puede omitir contemplar la depreciación monetaria (ya que sin la aplicación de un índice de ajuste, en épocas de deterioro del poder adquisitivo de la moneda, se afectaría el patrimonio del dañado y la reparación que merece)", BUERES, Alberto J., Código Civil y Comercial de la Nación, analizado, comparado y concordado. Hammurabi, Buenos Aires, 2015, p. 485/486. 
Estos procesos que aguardan respuestas en las Cámaras laborales demandan una justa solución, que podría venir de la mano de la declaración de inconstitucionalidad del art. 20 (ley 27.348), o de la aplicación del DNU 669/19 (art.3) ${ }^{29}$ y la Resolución 1039/19 (art. 1) ${ }^{30}$, que son normas más favorables (art. 9 LCT). Recomendamos la lectura del fallo "Lujan" ${ }^{31}$. Si bien no ignoramos la suerte corrida por el $\mathrm{DNU}^{32}$, a contrario de lo que aquí proponemos, los embates fueron dirigidos en favor de los trabajadores.

Tampoco desconocemos que la propuesta parece de difícil andamiaje en el marco de los precedentes "Espósito c/Provincia” (CSJN, 7/6/2016); “Martin c/Mapfre" (TSJ, sent. 30 20/2/14) y “Rosales C/ Interacción (TSJ, sent. 149 - 2/5/2019)" pero quizás la solución nos llegue de la mano del precedente "Aldorino"33, compensando el ajuste con una reducción en el componente retributivo de la tasa de interés.

\section{Intereses al fondo:}

Conforme hemos adelantado al desarrollar los objetivos del interés moratorio, la tasa de interés aplicable responde a dos objetivos, uno directo o particular y otro indirecto o general. Un ejemplo de ello es lo que acontece en los procesos de liquidación de las ART. Recordemos brevemente que el sistema de riesgos de trabajo ha previsto la creación de tres fondos, a saber: el Fondo de Garantía (art. 33 LRT), el Fondo de Reserva (art. 34 LRT) y el Fondo Fiduciario para fines Específicos (D. 590/97).

El Fondo de Garantía, administrado por la Superintendencia de Riesgos del Trabajo, se destina al pago de las indemnizaciones a cargo de empleadores insolventes (art. 29 de la ley 24.557). Este fondo se encuentra exento del pago de intereses (art. 19, párr. 5, decreto $334 / 96)^{34}$, lo cual ha sido fuertemente criticado por la doctrina al perjudicar a los trabajadores, siendo que el fondo es sobradamente solvente ${ }^{35}$.

Distinto el caso del Fondo de Reserva (art. 34 LRT), administrado por la Superintendencia de Seguros de la Nación, que destina sus recursos al pago de las prestaciones pendientes de ART liquidada y prevé soportar los intereses que acceden al crédito ${ }^{36}$. Y si bien el TSJ condena al pago de intereses por considerarlos accesorios del capital, reduce la tasa habitual -"Hernández"- al despojarla del componente retributivo y limitarla-a la tasa pasiva promedio del BCRA. El alto cuerpo justifica su decisión tras considerar la necesidad de proteger al fondo, en beneficio de todos los trabajadores afectados y temiendo que la tasa de intereses habitual lo torne insuficiente. Criterio que ha sido recientemente ratificado con la nueva integración del tribunal cimero. ${ }^{37}$

\footnotetext{
29 Las modificaciones dispuestas en la presente norma se aplican en todos los casos, independientemente de la fecha de la primera manifestación invalidante". (art. 3, Decreto 669/19).

30 “...alcanzando a todos los casos pendientes de liquidación, independientemente de la fecha de la primera manifestación invalidante" (art. 1, Res. 1039/19). 31 Cámara Única del Trabajo de Córdoba, Sala 5a, vocal Dr. Añcides Segundo Ferreyra, autos: "Lujan Darío Gabriel c/Galeno ART S.A. - Ordinario enfermedad", consultada el 10/4/2020 en https://www.erreius.com/Jurisprudencia/documento/20191119122308855).

32 Declarado inconstitucional (Dr. SEGURA, Alejandro. Juez nacional de $1^{\circ}$ inst. 44. Autos: "FERNANDEZ Miguel A. C/. EXPERTA ART SA s/ACCIDENTE - LEY ESPECIAL. - 10/2019)” y suspendida su aplicación por cautelar en amparo (Juzgado Nacional de $1^{\circ}$ instancia, n 76. (09/10/2019) “Colegio Público de Abogados de Capital Federal c/Estado Nacional Poder Ejecutivo s/Acción de amparo), todo el primer día de su vigencia (ART. 5 CCCN).

33 TSJ "ALDORINO" ob, cit.

34 En autos la Corte mando dictar una nueva sentencia, atento que la Cámara que intervino dispuso la condena a cargo del Fondo de Reserva cuando debió condenar al Fondo de Garantía, y si bien el tribunal cimero no resolvió la cuestión de fondo, advirtió sobre la existencia de la norma que eximen el pago de los intereses y esto se interpreta como un guiño favorable a su aplicación. CSJN (11/10/18) recurso de hecho en autos "Villanueva, Silvia Marcela y otros cl La Gruta S.R.L. s/ accidente".

35 SCHICK, Horacio “Régimen de Infortunios Laborales”, cuarta edición, David Grimberg, Bs. As., 2017, pag. 682.

36 Véase la parte que dice: "teniendo en cuenta lo previsto en la Constitución Nacional así como por los Tratados Internacionales antes citados, corresponde establecer que la obligación del Fondo de Reserva de la LRT comprende la satisfacción de los intereses, por ser un accesorio de la obligación principal” (considerandos del Decreto 1022/17).

37 TSJ, sentencia 6,11/2/2020, con voto del Dr. Angulo en "Pattacini, Carlos Augusto c/ Aseguradora de Riesgos de Trabajo Interacción S.A. y otro".
} 
No han corrido igual suerte las costas, que si bien exceden el objeto de estudio de este apunte, el decreto 1022/2017 determina que los importes relativos a costas y gastos causídicos, como así también, los montos de las indemnizaciones que se reconozcan con fundamento en el derecho común, exceden el alcance de la cobertura a cargo del Fondo, debiendo -de corresponder reclamarse en el procedimiento judicial relativo a la liquidación de la Aseguradora de Riesgos del Trabajo respectiva.

\section{El curso del intereses - Dies a quo/dies ad quem:}

El dies a quo en los procesos laborales que se resolvieron en las distintas salas de la Cámara Única del Trabajo de Córdoba, no ha sido fijado con idénticos criterios. Pero la decisión no debiera ser cuestionada salvo el vicio en su fundamentación que habilita un planteo por arbitrariedad de sentencia ${ }^{39}$.

Seguidamente abordaremos el tema de los reclamos derivados de la Ley de Riesgos de Trabajo (ley 24.557).

En el marco de los procesos basados en pretensiones indemnizatorias previstas en la LRT (art. 11, 14, 15, 17 y 18 de la LRT) los tribunales adoptan parámetros diferentes. Así encontramos precedentes que determinan el curso del interés a partir de la fecha del daño, se basan en el art. 2, $3^{\circ}$ párr. de la Ley $26.773^{40}$, art. 11, inc. 2 ley $27.348^{41}$ y en el art. $1748 \mathrm{CCCN}^{42}$, mientras que otros precedentes escogen su computo a partir de la fecha de disposición ${ }^{43}$ (art. 768 CCNC) ${ }^{44}$.

A nuestro entender el momento a partir del cual debe comenzar el curso del interés no es un problema menor, porque puede llevar a decisiones injustas y "licuar" o "pulverizar" el crédito; es por ello que adelantamos nuestra adhesión a la primera hipótesis planteada.

Uno de los argumentos que sustentan nuestra posición radica en el hecho de que las prestaciones indemnizatorias de la LRT nacen como obligaciones de valor ${ }^{45}$ por cuanto no se pueden cuantificar ad initio sino que requieren un proceso de determinación que, una vez concluido, habilita poner a disposición las indemnizaciones. Luego y en el derecho común, vemos que la distinción entre obligación de valor y de dar suma de dinero,

\footnotetext{
38 Las expresiones latinas "dies a quo" y "diez ad quem" refieren, respectivamente, al inicio y finalización de un plazo. Cuando hablamos de curso de los intereses nos referimos al lapso temporal que transcurre entre el dies a quo y el dies ad quem durante el cual corresponde su devengamiento.

39 "El momento en que debe comenzar el computo inicial de los intereses constituye una cuestión de hecho, variable en cada proceso y por ello ajena a su revisión en esta instancia. Solo cuando dicho momento, frente a idéntica situación fáctica resulta elegido discrecionalmente, se obliga a esta sala a ejercer la función unificadora" (TSJ, sent. 242/15 "Rodríguez, José Alberto c/Berkley Internacional ART S. A. - Ordinario - Accidente").

40 “...El derecho a la reparación dineraria se computará, más allá del momento en que se determine su procedencia o alcance, desde que acaeció el evento dañoso o se determinó la relación causal adecuada de la enfermedad profesional...” (art. 2, 3º párrafo, ley 26.773).

41 "Desde la fecha de la primera manifestación invalidante y hasta el momento de la liquidación de la indemnización por determinación de la incapacidad laboral definitiva...el monto del ingreso base devengara un interés...” (art. 11, ley 27.348).

42 "Curso del interés. El curso del interés comienza desde que se produce cada perjuicio" (art. 1748 CCCN)

43 Nos referimos a la fecha a partir de la cual el deudor (ART o EA) debe poner las indemnizaciones a disposición de los damnificados. Fecha que no es clara, porque las diferentes reglamentaciones se contradicen entre sí y prevén momentos diferentes que van desde los 15 (quince) días corridos (art. 4 , Decreto 472/14) contados desde la notificación de la homologación (art. Res. 104/98), o los 30 (treinta) días corridos desde que la prestación debió ser abonada o prestada (art. 2, Res. 414/99) o los 5 (cinco) días contados a partir de la notificación de la homologación (art. 13 y 26 res. 298/17) o el plazo previsto por la Resolución no 1039/19 (publicada en el boletín oficial 13/11/2019) que viene a reglamentar el art. 12 de la Ley 24557 y define que por puesta disposición se entiende la fecha de suscripción del acuerdo administrativo (art. 4 Res. 1039/19).

44 "Interés moratorio. A partir de su mora el deudor debe los intereses correspondientes..." (art. 768 CCCN).

45 A diferencia de las de dar dinero que están determinadas o son determinables -por una simple operación aritmética- desde que nacen. En las de valor el deudor sabe que debe, pero aun no puede precisar el importe y por ende no puede pagar, mientras que las de dar dinero el deudor sabe que debe cierta cantidad de moneda porque se encuentra directamente expresada (v. gr., \$1000), o porque su determinación se logra con un cálculo aritmético (art. 765 del $\mathrm{CCCN})$.
} 
se utiliza para establecer el dies a quo del curso del interés. Para las de valor se toma la fecha del perjuicio (art. 1748 CCCN) mientras que para las de dar dinero la mora del deudor (art. $768 \mathrm{CCCN})^{46}$.

Podemos decir que la obligación de valor aspira a convertirse en una de dar dinero y que son de valor por cuanto entre la fecha del daño y la fecha de determinación transcurre un periodo que podríamos denominar "periodo ventana". Este lapso temporal que trascurre desde la fecha en que el trabajador resultó víctima de un accidente o enfermedad laboral (Primera Manifestación Invalidante o PMI), incluye habitualmente un periodo de curación - (Incapacidad Laboral Temporaria o ILT - art.10 ley 27.348), seguido de un procedimiento administrativo o judicial de determinación y cuantificación del daño (art.1 ${ }^{\circ}$ ley 27.348 , res. $298 / 17,899 / 17,2^{\circ}$ ley 27.348 y $3^{\circ}$ de la ley 10.456 ) y que finaliza en el momento de la disposición de la indemnización.

Además, si trazamos un parangón con el derecho común, vemos que busca garantizar una "reparación plena, total o integral"47 (art. $1740 \mathrm{CCCN}$ ) ${ }^{48}$, objetivo que fue ganando terreno en la LRT a través de una constante mejorar en las prestaciones cubiertas y una amplificación del espectro del daño resarcible ${ }^{49}$ y que nos lleva a contemplar, a través del interés, el daño adicional provocado por la demora ${ }^{50}$.

Otra perspectiva la encontramos al estudiar la clasificación efectuada por el cimero tribunal cordobés, que advierte que el interés moratorio se compone de un interés indemnizatorio o resarcitorio calculado a partir del momento del daño ${ }^{51}$ y que se diferencia del "pu-

46 A ello responde la ubicación normativa de ambas disposiciones que se ubican estratégicamente dentro del CCCN. Mientras el art. 1748 se ubica en el título V, sección $4^{\text {a }}$, donde se desarrollan las pautas aplicables a la reparación indemnizatorias u obligaciones de valor, el art. 768 se ubica dentro del título I, capitulo 3 , sección 1 , párrafo $6^{\circ}$, dedicado a las "obligaciones de dar dinero".

47 Ha dicho el alto cuerpo: “...radica en el principio rector de la responsabilidad civil cual es el de la reparación plena e integral, en cuya virtud la víctima debe ser resarcida de "todo" daño causado, de la manera más completa posible. En la responsabilidad civil rige el principio de reparación plena o integral para lo cual los intereses al ser accesorios de la obligación principal (reparación del daño) constituyen su expresión más concreta, pues tienden a preservar la integridad de la indemnización a que tiene derecho la víctima (arts. 106 y 1078 C.C.). Surge entonces la necesidad de reparar todos los rubros que componen la obligación principal, con su correspondiente interés", TSJ, sent. 83 (16/8/2016), autos "Suárez, Jorge Eduardo c/ Galván, Carlos Andrés - Ordinario Daños y perj. - Accidentes de tránsito - Recurso de casación".

48 Se ha expuesto: “...la adecuada protección del derecho a la vida y a la integridad psicofísica de las personas exige que se confiera al principio alterum non laedere toda la amplitud que éste amerita, así como evitar la fijación de limitaciones en la medida en que impliquen "alterar" los derechos reconocidos por la Constitución Nacional (art. 28). En ese entendimiento, cabe señalar que es la violación del deber de no dañar a otro lo que genera la obligación de reparar el menoscabo causado y tal noción comprende todo perjuicio susceptible de apreciación pecuniaria que afecte en forma cierta a otro en su persona, en su patrimonio y/o en sus derechos o facultades. Dicha reparación no se logra si los daños subsisten en alguna medida, motivo por el cual la indemnización debe ser integral (conf. Fallos: 324:2972 y arg. Fallos: 326:2329)". CSJN, (27/11/2012), autos: "Rodríguez Pereyra, Jorge Luis y otra c/Ejército Argentino si daños y perjuicios".

49 A modo de ejemplo recordemos las mejoras introducidas por el decreto 1278/00, el decreto 1694/09, el art.3 ley 26.773, art. 11 ley 27.348 , entre otros.

50 "La fuente de los intereses moratorios es distinta a la de la reparación a la que accede; mientras que los ítems resarcitorios se deben por causa del daño derivado del hecho lesivo primario, la obligación de pago de intereses moratorios responde a otro hecho dañoso, claramente distinto, cual es el no cumplimiento oportuno de la obligación de reparar el daño... .... Los intereses no se deben en razón del daño básico o primordial que ha generado el nacimiento de la obligación resarcitoria principal, sino en función de un daño adicional: el daño moratorio desencadenado por la tardanza en la reparación" (conf. Zavala de González, Matilde - Moreno, Graciela Melania, "Los intereses en la responsabilidad civil”, JA, 1985-IV-713), TSJ, sentencia 4 (26/4/2013) "Carletti Oscar Dionisio c/ Empresa General Urquiza SRL - Ordinario - Daños y perjuicios - Recurso de casación”; "La tardanza en la cancelación de la deuda genera automáticamente un nuevo daño - de naturaleza moratoria- que se añade al provocado originariamente." TSJ (Dr. Rubio, Blanc, Sesin) - A. I. 355 (28/8/2017),autos: "Agüero José Antonio c/ García María del Rocío y otro - Ordinario - Accidente con fundamento en el derecho común-Recurso de casación."

51 Reeditando palabras del TSJ, decimos que "Los compensatorios o lucrativos son los que se deben por el goce del capital ajeno. Constituyen, al decir de Pizarro y Vallespinos, los que “...se adeudan como contraprestación o precio por la utilización de un capital ajeno" (PIZARRO, Ramón - VALLESPINOS, Gustavo, Instituciones de Derecho Privado - Obligaciones, Hammurabi, Bs. As., 1999, T. 1, p. 403). Los moratorios se deben en concepto de indemnización por el menoscabo que sufre el acreedor frente a la mora del deudor en el pago de su obligación dineraria. Representan la reparación del retardo imputable al obligado. Su fundamento radica, entonces, en la circunstancia de que el deudor -con su incumplimiento- priva ilegítimamente al acreedor de su derecho a percibir el capital y, como consecuencia de ello, debe reparar el daño causado. Los punitorios, finalmente, importan una sanción por el incumplimiento oportuno de una obligación. Los intereses que integran la reparación de un daño causado extracontractualmente -por regla- son los denominados moratorios, y tienen por primordial objeto resarcir la falta de cumplimiento oportuno de la obligación de indemnizar. Así lo han apuntado juristas de prestigio afirmando que: "los intereses indemnizatorios o resarcitorios son también moratorios pues al responsable se le impone la obligación de reparar el daño causado a partir del momento mismo de su producción, operando la mora automáticamente desde ese instante" (PIZARRO, Ramón D., Los intereses 
nitorio" 52 que importan una sanción frente al incumplimiento oportuno de la obligación -en LRT a partir de la disposición ${ }^{53}$-. Como vemos el interés resarcitorio o indemnizatorio no viene a castigar una conducta renuente del deudor, sino a compensar el efecto dañino que necesariamente provoca el paso del tiempo.

En conclusión, una indemnización que aspire a ser completa debe incluir el curso del interés a partir del origen del daño, contemplando el interés resarcitorio y el punitorio ${ }^{54}$.

El cómputo del interés debe contemplar íntegramente la demora, incluido el periodo ventana que transcurre desde que la obligación de valor se transforma en una obligación de dar dinero. Aspecto que ha sido contemplado en la ley 27.348 y que debiera ser aplicado, por analogía o similitud, a los procesos regulados en marcos normativos anteriores. De lo contrario el importe calculado a valor histórico sufriría, desde la ocurrencia del daño hasta su cuantificación, la pérdida de su valor adquisitivo frustrando la posibilidad de obtener una reparación plena e integral.

\section{El dies ad quem:}

Para completar el análisis sobre el curso del interés, entendemos que el dies ad quem surge a partir de la fecha en que el crédito está en condiciones de percepción. Esto es a desde el momento en que el acreedor puede efectivamente disponer del monto de la deuda. ${ }^{55}$

\section{IV. -Anatocismo:}

Por último nos ocuparemos de la capitalización del interés o interés del interés, donde el interés devengado se suma al capital y el resultado conforma un nuevo capital que será la base para el cálculo de futuros intereses (capital + intereses de capital = nueva base de futuros intereses).

Cuando hablamos de anatocismo nos circunda la idea de usura o deudas de cumplimiento imposible, pero si concebimos despojarnos de los preconceptos despectivos, podremos

\footnotetext{
en la responsabilidad extracontractual, Sup.Esp. Intereses 02/07/2004, 75 - Responsabilidad Civil Doctrinas Esenciales 01/01/2007, 1553; íb. ZAVALA DE GONZALEZ, Matilde - MORENO, Graciela Melania, Los intereses en la responsabilidad civil, JA, 1985-IV-713; entre otros). El fundamento de ello radica en el principio rector de la responsabilidad civil cual es el de la reparación plena e integral, en cuya virtud la víctima debe ser resarcida de "todo" daño causado, de la manera más completa posible "En la responsabilidad civil rige el principio de reparación plena o integral para lo cual los intereses al ser accesorios de la obligación principal (reparación del daño) constituyen su expresión más concreta, pues tienden a preservar la integridad de la indemnización a que tiene derecho la víctima (arts. 106 y 1078 C.C.). Surge entonces la necesidad de reparar todos los rubros que componen la obligación principal, con su correspondiente interés" (TSJ Cba., Sala Penal, Sent. No 18 del 09/03/05). Sin embargo, la fuente de los intereses moratorios es distinta a la de la reparación a la que accede; mientras que los ítems resarcitorios se deben por causa del daño derivado del hecho lesivo primario, la obligación de pago de intereses moratorios responde a otro hecho dañoso, claramente distinto, cual es el no cumplimiento oportuno de la obligación de reparar el daño. Así lo enseña autorizada doctrina, señalando que: "Los intereses no se deben en razón del daño básico o primordial que ha generado el nacimiento de la obligación resarcitoria principal, sino en función de un daño adicional: el daño moratorio desencadenado por la tardanza en la reparación” (Conf. ZAVALA DE GONZALEZ, Matilde - MORENO, Graciela Melania, Los intereses en la responsabilidad civil, JA, 1985-IV-713). En consecuencia, la obligación de pago de intereses moratorios no es "necesaria" frente a un daño; por el contrario, es "eventual" toda vez que sólo surge si media un intervalo temporal entre el daño a resarcir y el momento en que se compensa el menoscabo. En cambio, si el perjuicio no se ha producido, o si acaecido es inmediatamente compensado por el responsable, no se genera la obligación de pago de intereses resarcitorios." " sic, énfasis agregado. TSJ, sent. 83 (16/08/2016), autos "Suarez, Jorge Eduardo c/ Galvan, Carlos Andrés - Ordinario - Daños y perj. - Accidentes de tránsito - Recurso de casación - Expediente No 701263/36"

52 "Los punitorios, importan una sanción por el incumplimiento oportuno de una obligación”,TSJ, autos “Suarez, Jorge Eduardo c/ Galván”.

53 Entendida como el momento en que la indemnización debió ser puesta a disposición de los damnificados.

54 "El planteo referido a los intereses - que según la demandada debieron comenzar a correr una vez vencido el plazo de quince días posteriores a la notificación a la aseguradora del dictamen donde se determina el porcentaje de incapacidad-, deviene inadmisible, pues no demuestra el error en la conclusión del juzgador que ordeno los accesorios legales desde que la suma es "debida" - fecha del accidente",TSJ, sent. 34/14, "Pereyra, Marcos Emanuel c/Asociart ART S. A. - ordinario - accidente (Ley de Riesgos)".

55 "El depósito efectuado por el demandado no reviste la calidad de pago como medio de extinción de las obligaciones en los términos de los art. 724 y 725 C. C. Esto es así pues aquel, se supedito a las resultas de la queja interpuesta ante la CSIN......En tales condiciones, el computo de los intereses debe efectuarse hasta que el dinero depositado en concepto de capital, honorarios y accesorios se encontraba disponible para los acreedores", TSJ, sent. 127/09, "Correa, Domingo Ramón c/John Wyeth Laboratorios S. A. - Ordinario", publicado por LASCANO, Eduardo y CALVIMONTE, Beatriz en "Derecho del Trabajo- Interpretación Judicial”, Advocatus, Córdoba, 2018, p. 543.
} 
apreciar su justificación y utilidad práctica. Esto porque cuando el instituto es "razonablemente empleado, constituye una justa retribución para el acreedor que se ve impedido de utilizar su dinero a causa de la mora de su deudor y, como tal, integra su derecho de crédito". 56

Pero el anatocismo, por regla inaplicable ${ }^{57}$, procede en las siguientes hipótesis: a) acuerdo expreso de partes; b) obligación demandada judicialmente; c) obligación liquidada judicialmente; d) disposición legal.

En materia de LRT está prevista la capitalización del interés (art. 11, inc. 3, ley 27.348 - art. 770, inc. d, CCCN). Según el texto normativo luego de la determinación de la liquidación, el deudor debe poner a disposición de los beneficiarios el monto de la indemnización, caso contrario incurre en mora ${ }^{58}$ habilitando la capitalización los intereses ya devengados ${ }^{59}$.

La determinación de la liquidación puede formularse en una etapa administrativa o judicial. Si bien no hay acuerdo sobre el momento de la mora, las Comisiones Médicas prevén 5 (cinco) días contados a partir de la notificación de la homologación (art. 13 y 26 res. 298/1760), pese a que la resolución $n^{\circ}$ 1039/19 (publicada en el Boletín Oficial 13/11/2019) le prevé a partir de la suscripción del acuerdo administrativo o liquidación en los demás casos -judicial- (art. 4 Res. 1039/19) ${ }^{61}$.

Frente a esta circunstancia quizás debe imponerse la Res. 1039/19, dictada en último término y más favorable al trabajador (art.9, LCT).

En el caso de determinación judicial de la deuda entendemos que la capitalización se producirá en los términos del art. 770 inc. c) ya analizado.

\section{V. - Conclusiones finales}

Resulta claro que conceptos como "intereses", "actualización monetaria", "tipo de tasa de interés" y "anatocismo" difieren ontológicamente. Sin embargo, constituyen en la actualidad el conjunto de herramientas con los que cuenta el juzgador a fin de lograr una indemnización justa.

Es necesario determinar parámetros de previsibilidad jurídica para que los acreedores puedan tener garantías del debido resguardo de sus créditos bajo el paradigma de la integralidad de un legítimo resarcimiento, en un contexto de economía inestable e inflacionaria.

\footnotetext{
56 TSJ, AI n 88 (9/5/2013) autos: "Banco Bansud S. A. c/Allendez Ana A. y otros - Ordinario - Cuerpo de copias - Recurso de casación."

57 Se expresa que “... no se deben intereses de los intereses...” (art. 623 del CC según la ley 23.928 y art. 770 del CCyCN).

58 art. 12 Ley 24557, según modificación introducida por el art. 11 Ley 27348

59 A la actualización del salario por medio del índice RIPTE se le suma un interés de tasa legal, desde la PMI hasta la fecha de la liquidación. Luego el importe así calculado se capitaliza (art. $770 \mathrm{CCyCN}$ ) para dar lugar a un nuevo interés, de tasa legal (art. 768, inc. "b" CCyCN), a partir de la mora.

60 "A partir de la notificación del acto de homologación, la Aseguradora de Riesgos del Trabajo, el Empleador Auto asegurado o el Empleador No Asegurado deberá poner a disposición del damnificado el importe de la indemnización en la cuenta bancaria oportunamente declarada, dentro del plazo de cinco días de conformidad con lo establecido en el art. 4 del Anexo I de la Ley Complementaria de la Ley sobre Riesgos del Trabajo." (art. 13, 26, resolución 298/17 $-24 / 02 / 2017)$

61 "Establécese que a los fines del cálculo del interés del Artículo 12 inciso 2 de la Ley N²4.557, deberá entenderse como fecha de puesta a disposición: a) en los casos en los que se hubiese llegado a un acuerdo, la fecha de suscripción del mismo; b) en todos los demás casos, la fecha de liquidación de la prestación dineraria" (art. 4, Res. 1039/19).
} 